\title{
CARTAS AOEDITOR
}

Pattern reversal visual evoked potentials in migraine subjects without aura. P.E. Moreira Filho, A.M. Dantas. Arq Neuropsiquiatr 1994, 52 (4): 484-488.

O Editor recebeu a propósito do artigo carta de colega neurofisiologista. A carta recebida e a resposta dos autores do artigo são transcritas a seguir.

\section{Senhor Editor:}

Trabalhando com potenciais evocados desde 1982, li com interesse o artigo referido e gostaria de comentar alguns aspectos fundamentais, que poderiam comprometer a natureza do trabalho.

1) Revendo recentemente literatura sobre enxaqueca e potenciais evocados, a área dos visuais pareceu-me assaz perturbada por trabalhos tecnicamente não comparáveis (embora o título dos trabalhos até possa dar impressão diferente); aparentemente, o presente trabalho também segue esse tendência, não conseguindo sanar defeitos de base, como se poderá ver a seguir.

2) Pode-se inicialmente criticar a seleção dos pacientes: há diferentes proporções de pacientes do sexo masculino e feminino, e sabe-se que os valores normativos são diferentes conforme o sexo (mulheres, como grupo, mostram latências menores e amplitudes maiores); são ainda descritos efeitos da idade na população acima de 50 anos, o que poderia complicar sua inclusão junto aos pacientes mais jovens. Porém, o mais grave, não há quaisquer referências à composição do grupo controle. Que critérios foram usados para selecionar a população normal ? Pacientes com cefaléia ou um episódio de enxaqueca há muitos anos podiam fazer parte do grupo normal ? Quais os valores aceitos como normais no laboratório dos autores para quadrados branco/preto e verde/vermelho ? Não são mencionados no trabalho (seguramente não devem ser iguais).

3) Também há confusão quanto a aspectos técnicos: uma TV de 20 polegadas $(50,8 \mathrm{~cm})$ corresponde a um ângulo visual de cerca de 30 graus a 1 metro de distância; quadrados de $4 \times 4 \mathrm{~cm}$ a 1 metro correspondem a ângulo visual pouco maior do que 2 graus (cerca de 2 graus e 20 min) e não 30 graus, como se deprende da leitura. E aí surge outro problema: acima de 2 graus a luminância não se mantém constante e há mistura dos resultados do padrão reverso com os do flash, o que inclusive compromete seu uso clínico (C W Erwin, Am J EEG Technol 1980, 20: 161-184; K H Chiappa, Evoked Potentials in Clinical Medicine). Desta forma, fica comprometida a assertiva introdutória que o padrão reverso é mais robusto que o flash, verdadeira apenas quando houver extremo cuidado com aspectos técnicos.

Ao longo dos anos de trabalhos, não tem chamado nossa atenção o encontro de anormalidades do padrão reverso em pacientes com enxaqueca. Apesar da literatura mencionar que estudos populacionais habitualmente mostram diferenças, fica muito difícil sua valorizaçāo, pois a comparaçāo passa obrigatoriamente pela necessidade de fixar rigidamente os parâmetros técnicos e, assim, eliminar causas de erro.

Esperando contribuir,

Atenciosamente

Francisco José C. Luccas, Médico - Neurofisiologia Clínica

São Paulo, 14-dezembro-1994. 


\section{Senhor Editor:}

Agradecemos por ter nos dado a oportunidade de tentar esclarecer as questões levantadas pelo neurofisiologista Dr. Francisco J. C. Luccas sobre o nosso artigo ${ }^{5}$.

No item 1) - os potenciais evocados visuais (PEV) obtidos em pacientes com enxaqueca obedeceram a várias técnicas no período de 1959 a 1991, conforme citados em nosso trabalho contudo, somente comparamos nossos resultados com aqueles obtidos com técnica semelhante como as de Mariani et al..$^{3,4}$ explicitamente mencionados no texto.

No item 2) - as diferentes proporções de pacientes do sexo masculino e feminino são evidentes e esperadas, pois a afecção em estudo é a migrânea que estatisticamente predomina no sexo feminino em qualquer de suas formas clínicas. O neurofisiologista afirma que "mulheres apresentam latências menores e amplitudes maiores". É provável que a amplitude seja maior nos pacientes do sexo feminino em relaçăo ao masculino, entretanto apesar de terem sido medidas em todos os nossos enfermos, näo foi o objetivo de nosso estudo e sim a latência da onda P100 do potencial evocado visual padrão reverso (PEV-PR), claramente exposto na introdução da nossa pesquisa. Quanto às variações de latência com o sexo há controvérsias, de acordo com Chiappa ${ }^{1}$, citado pelo neurofisiologista. Mas mesmo aceitando como verdade a afirmativa que latência do PEV é menor nas pacientes do sexo feminino, estastisticamente esta diferença é desprovida de qualquer importância. Com relação à idade, só passam a ocorrer modificações na latência da onda P100 do PEV em indivíduos após os 60 anos $^{1.2}$. A propósito, so a título de exemplo, o paciente mais velho de nossa casuística é o Caso 9 (54 anos) que apresentou as latências da onda P100 do PEV- PR preto/branco e vermelho/verde dentro dos limites normais (vide Tabela pg 486), além da acuidade visual 20/20 em ambos os olhos. Por trabalharmos no Hospital Universitário Antonio Pedro da Universidade Federal Fluminense, foram escolhidos para grupo controle, estudantes de medicina, de enfermagem, funcionários do próprio hospital e acompanhantes, absolutamente saudáveis, sem nenhuma queixa de cefaléia principalmente enxaqueca. Foram selecionados 8 indivíduos do sexo masculino e 22 do feminino com idades entre 15 e 50 anos. Os valores normais para o PEV-PR preto e branco foram 92-108 ms (média de 99,2 ms) e para o PEV-PR vermelho e verde $94-109 \mathrm{~ms}$ (média de $100,9 \mathrm{~ms}$ ).

Item 3) - Nestre tópico o Dr. Luccas confunde o ângulo visual em relação a largura do monitor ( $\theta)$ que é o importante para o PEV e o ângulo visual em relação aos quadrados que compõem o padrão reverso $(\delta)$ que não tem o menor valor prático. A Figura 1 ajuda a compreender o que foi dito acima.

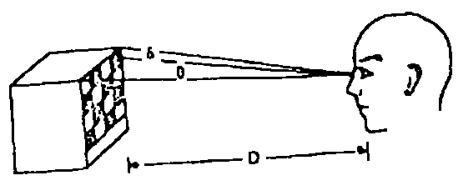

Fig 1. Demonstraçāo dos ângulos $\theta$ e $\delta$

De acordo com a figura 1 , o ângulo visual $\theta$ é obtido pela seguinte equação:

$$
\theta=\frac{360}{2 \pi} \times \frac{R}{D}
$$

em que $R$ é a largura do monitor (no nosso caso $50,8 \mathrm{~cm}$ ), D distância dos olhos do paciente ao monitor (no nosso trabalho foi de $100 \mathrm{~cm}$ ) e $\pi 3,1416$. Portanto, o nosso ângulo $\theta$ foi de $29,10^{\circ}$ 
que aproximamos para 30". O ângulo $\delta$, como dissemos, é desprovido de valor na prática, mas como foi mencionado pelo Dr. Luccas só para esclarecimento é obtido pela fórmula:

$$
\delta=\quad \frac{\theta}{\text { tamanho do quadrado do padrão reverso }}
$$

Outra confusão que o neurofisiologista faz é quanto a luminância, que é fornecida pela fonte luminosa (no caso o monitor de PEV) que está regulada para ser constante, podendo ser alterada somente se o examinador assim o desejar. Temos de discordar do neurofisiologista quando afirma que na introdução de nosso trabalho relatamos que o "padrão reverso é mais robusto que o flash". Não fizemos tal asserção e novamente asseguramos que em nenhum momento comparamos o nosso trabalho com outros que tenham utilizado técnicas diferentes.

Para terminar, agradecemos ao Dr. Francisco J.C. Luccas pela atenção e paciência com que leu o nosso trabalho. Caso tenha alguma outra dificuldade o Serviço de Eletrofisiologia Ocular da Universidade Federal Fluminense, chefiado por um dos autores (A M D), estará a disposição para qualquer esclarecimento.

Cordialmente,

Pedro F. Moreira Filho, Professor Adjunto IV de Neurologia, UFF

Adalmir M. Dantas, Professor Titular de Oftalmologia, UFF

Rio de Janeiro, 12-janeiro-1995.

\section{REFERENCLIAS}

1. Chiappa KH. Evoked potentials in clinical medicine. Ed 2. New York: Raven Press, 1990, 1-171.

2. Guérit J-M. Les potentiels évoqués. Paris: Masson, 1991, 55-86.

3. Mariani E, Moschini V, Pastorino G, Rizzi F, Severgnini A, Tiengo M. Pattern reversal visual evoked potentials and EEG correlation in common migraine patients. Headache 1988, 28: 269-271.

4. Mariani E, Moschini V, Pastorino G, Rizzi F, Severgnini A, Tiengo M. Pattern reversal visual evoked potentials (VEP-PR) in migraine subjects with visual aura. Headache 1990, 30: 435-438.

5. Moreira PF Filho, Dantas AM. Pattern reversal evoked potentials in migraine subjects without aura. Arq Neuropsiquiatr 1994, 52: 484-488. 